\title{
Transformation and Upgrading Innovation of University Student Travel Agency: An Empirical Study in Shenzhen
}

\author{
Yanhong Liu, Hongfang Zhan \\ Tourism and Culture Department \\ Normal College Shenzhen University \\ Shenzhen China
}

\begin{abstract}
With the development of economy and the change of university students' consumption concepts, university students tourism market has developed rapidly. For the sustainable and healthy development of university student travel agencies, the paper takes Shenzhen University as an example, carries out questionnaire survey and SWOT analysis, combines the actual situation of the cases to propose specific and operational innovation strategies for the transformation and upgrading of university student travel agencies.
\end{abstract}

Keywords-University travel agency; SWOT analysis; Transformation and upgrade; Innovation research

\section{INTRODUCTION}

Nowadays, Tourism has gradually become an important part of university students' lives. With the rapid development of the tourism market, university students travel agencies came into being. However, due to lack of funds, experience, and other reasons, they have verity shortcomings. In order to investigate the status quo of students' travel and the current situation of university student travel agencies, we conducted a full-scale, multi-angle investigation and research. The research activity takes Shenzhen University as an example, proposes feasible suggestions for the transformation, upgrading, and innovation of university travel agencies through the issuance of survey questionnaires, the visits to student travel agencies and combination with research methods such as SWOT and case studies.

\section{LITERATURE REVIEW}

From the current academic research on university student travel agencies, the research content mainly focuses on the importance of developing college students travel market and the characteristics of student travel activities [1-3]. In terms of research purposes, it is focused on how travel agencies develop the tourism market for college students and use specific college travel agencies as examples [4].

From above relevant documents and surveys, this article conducts systematic study of college student travel agencies, taking Shenzhen University Travel Agency as an example. After a comprehensive analysis of operating conditions of its travel agencies, we propose corresponding measures in light of the actual situation of Shenzhen University. It can provide reference for the transformation and upgrading of college student travel agencies.

\section{RESEARCH METHODS}

The research on college and university student travel agencies is still at an exploratory stage, and there are few relevant literature materials at present. Therefore, in order to meet the needs of research, this article uses case studies, SWOT analysis, and questionnaire surveys to conduct field trips and research on college student travel agencies in Shenzhen University.

\section{A. Case Selection}

This article is based on four travel agencies in Shenzhen University (hereinafter referred to as STA, namely Shenzhen University Travel Agencies) as a case study. They are Shenzhen University's Yifeng Culture Co., Ltd., the EEL Travel platform for travel, the student practice base for the Tourism and Culture Department of Shenzhen University, and U-Tour Travel Agency.

Among them, Yifeng Culture Co.Ltd. is the main destination for the employees of the school, the EEL Travel is mainly for students and faculties, and U-Tour Travel Agency is the main route for low-cost private custom courses and recommended by college students. The Department of Tourism and Culture of Shenzhen University, as a student practice base, has no practical operation because of its main function as a trainee training for university students.

\section{B. Data Collection}

In order to accurately understand the current status of Shenzhen University students' travel, we conducted targeted market research and analysis for Shenzhen Travel Agency. This sample survey sent a total of 200 questionnaires to Shenzhen University undergraduates. 178 questionnaires were returned, and the qualified rate of the questionnaires was $89 \%$. The investigation time was from December 10 to December 20, 2017. The sample survey work was carried out in strict accordance with the "Statistics Law", "Tourism Statistical Survey System" and international conventions. The survey data 
was real and reliable, and the results were of certain reference value.

\section{Analysis Method}

In this study, the SWOT analysis method is used. Among them, S (strengths) and $\mathrm{W}$ (weaknesses) are internal factors, and $\mathrm{O}$ (opportunities) and $\mathrm{T}$ (threats) are external factors. The SWOT analysis method is based on the situation analysis under internal and external competitive environment and competition conditions. The research matrix is constructed by listing the research results, so as to visually demonstrate the overall situation of the development of college student travel agencies in Shenzhen University and put forward feasible opinions and suggestions.

\section{CASE STUDY RESUlts}

Through data analysis and SWOT analysis, this paper summarizes the current state of the management of deep travel agencies, involving self-positioning development, internal and external factors and development strategies. The following is brief summary of the four aspects involved in the SWOT analysis.

\section{A. Strengths}

\section{1) Financial and policy support}

Shenzhen University is a university that supports innovation and encourages entrepreneurship. It provides great financial and policy support for college student travel agencies, offers entrepreneurial park office space and venture capital support for projects that will be started during the school year. [5]

\section{2) Broad prospects of student market}

Shenzhen University currently has over 25,000 students. With the improvement of living standards and improvement of consumer attitudes, more and more students are willing to travel and spend on travel. The questionnaire survey shows that $88.9 \%$ of the students had travel consumption behavior during the university.

\section{3) Sufficient free time for students}

College students have plenty of vacations. Taking Shenzhen University as an example, there are weekends, Qingming festival, Duanwu festival, National Day holidays, winter, spring and summer vacations. There are average of 178 days as vacation each year. Students have enough leisure time to carry out tourism activities.

\section{4) Strong desire to travel}

College students are in a period of intense curiosity and adventure. They have strong desire to travel home and abroad. Questionnaire survey results show that over $80 \%$ of students expressed their willingness to travel under economic conditions. In addition, $52 \%$ of students said that they would travel at least once a year on average.

\section{B. Weaknesses}

\section{1) Small and scattered overall layout}

Although several travel agencies of Shenzhen University have different main directions, due to the establishment of the previous period and the current operations are mainly carried out by students, the overall presentation is small and scattered, and it lacks strategic layout. Compared with the large travel agencies on the market, there are shortcomings in the procurement of tour guides, tickets, transportation, and catering. Currently, the most famous and best-developed travel agency in the university is Shenzhen University Tourism Company. However, it lacks its own tourism resources, mainly operates through wholesale and resale of other travel agency products. For tour guide personnel resources, the use of outsourcing and temporary employment are its main forms. In the tourist on season, it is difficult to guarantee the quality and qualifications of tour guides.

\section{2) Blind imitation and fuzzy positioning}

There are blind imitations and vicious competition issues in several major travel agencies within STA. As university student travel agency, the service targets are Shenzhen University faculty, staff and students. Therefore, in the positioning of tourism products, the characteristics of consumers should be clearly defined, and products should be launched according to the needs of consumers. However, the survey found that market homogenization of STA is serious. As for the same price of travel products, consumers are more inclined to choose large scale, good brand travel agencies.

\section{3) Short boards in brand promotion}

Shenzhen University's several major travel agencies have problems such as low visibility and ineffective measures in brand promotion. Taking Shenzhen University's Yifeng Culture Co., Ltd. as an example, the promotion of its products relied on the recommendation from the intranet's official website and the popular demo tablet. At present, it has not yet launched its own WeChat public number and website. The audience is relatively small, and it is rare to see tourism promotion activities in STA. While EEL Travel and U-Tour Travel mainly rely on its own WeChat public number to promote its products, it has not yet formed a relatively large brand influence.

\section{Opportunities}

1) Enterprise cooperation concept

In order to enrich the extracurricular life of faculties, university's trade unions provide various opportunities for them to travel periodically every year. Such trips were coordinated by the heads of the trade unions before being packaged to the off-campus travel agencies, and travel agencies were again seeking local acceptance agencies for product assembly and sales.

At present, Shenzhen University's Yifeng Culture Co, Ltd. has reached certain degree of cooperation with the trade unions. The tour group of faculties is entrusted to Shenzhen University's Yifeng Culture Co., Ltd. Who also assists the school's reception work, such as the exchange of visits by colleges and universities, party committees, and Youth League committees. 


\section{2) Ample inner business opportunities}

For broadening students' horizons and enriching their extra-curricular life, Shenzhen University strongly support different kinds international exchange programs. These projects are usually self-enrolled by students. After collecting statistics, student representatives are responsible for visas, airline tickets and other items, causing inconvenience to all parties. If STA can reach cooperation agreement and undertake relevant business, it will be a win-win model for university, students, and travel agencies.

\section{3) Shorthanded campus reception}

With the increase of cooperation and exchange opportunities among Shenzhen University, domestic and foreign institutions of various affairs, the ca has a large number of visitor reception opportunities.

The campus reception task is mainly responsible for the admissions office and the corresponding colleges, but due to staff shortages and other issues, the relevant teachers are usually conveyed to students of the Department of Tourism and Culture of Shenzhen University for reception.

Although there are obvious advantages in the professional ability of tourism students, there are main characteristics of "casual" and "temporary" for campus reception, it is seriously lack of professional operation, systematic processes, and indepth training. It is the "pain point" of campus reception difficulty.

\section{Threats}

1) Monopolistic competition on large-scale travel platforms

With the development of the Internet travel market, the development of large-scale online travel platforms is in full swing. Travel platforms such as Ctrip, TripAdvisor, Feizhu Travel etc., dominate the online travel market. Compared with the large-scale capital and large-scale operation of the largescale Internet travel platform, college students travel agencies are obviously not competitive.

\section{2) Influence of free travel of the individual}

Contemporary university students are keen on the Internet. While the travel market for college students is hot, more students use the power of the Internet to choose their own freedom. The development of the Travel Raiders community, such as the Ma fengwo, Beibaoke has also provided students with great convenience in their own travel. If STA does not innovate and upgrade, this predicament will be aggravated by the further development of the Internet.

\section{STA TRANSFORMATION AND INNOVATION STRATEGY}

SWOT strategic analysis of STA combines with the actual situation of the travel agency from investigation and study, shows that STA is facing important opportunity for transformation and upgrading, together with both challenges and opportunities (see Table 1). It should seize the opportunity in time, planning, transforming and upgrading with innovation.

TABLE I. SWOT ANALYSIS OF STA

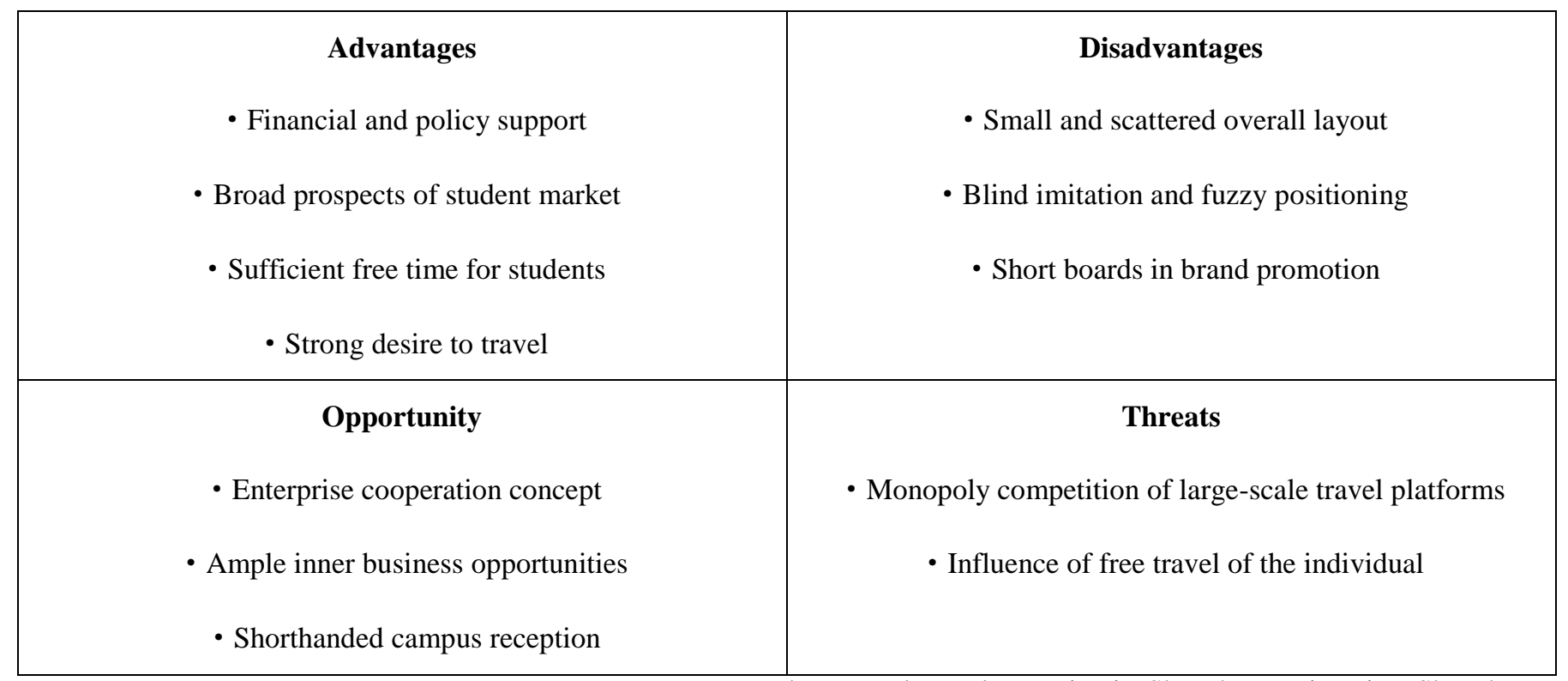

\section{A. Layout Strategy: Restructuring Resources in STA}

Major tourism platforms strive to become bigger and stronger in the development of the tourism market. In the wave of market economy, the allocation of resources, the survival of the fittest, and the integration of resources are the main ways to go. The four major travel agencies of STA have different target markets. However, the situation of "small" and "scattered" can no longer meet the needs of the college travel market. Among the several travel agencies in Shenzhen University, Shenzhen University's Yifeng Culture Co., Ltd. has the most abundant funds and largest scale and could be the role as a pioneer.

Each of the four major travel agencies in STA has its own advantages, and the target market is also different. It is proposed to integrate the resources of four travel agencies as one strong STA. This is a win-win approach for university travel agencies. 


\section{B. Product Strategy: Developing More Competitive Products}

Questionnaire survey results show that the main reasons for choosing college travel agencies are: cheap (76.97\%), personalized customization $(52.81 \%)$, safe and reliable $(42.7 \%)$.It can be seen that price, customization and security are the keys to the competitiveness of STA. Developing highquality and customized products for university students are important ways to increase market share. [6]

As far as tourism product types are concerned, special products such as group tours, study tours, outdoor adventure tours and academic tours can be developed. In terms of product mix, it is possible to develop full-package and half-package products. In the case of individual items such as admission tickets, it is possible to use the advantages of universities and reach a corresponding discount agreement with the scenic area to provide students with preferential products.

\section{Alliance Strategy: Strengthening School-Enterprise Cooperation}

The long-term development of STA can't succeed without the joint efforts of schools and travel agencies. From university point of view, it should provide strong support for the travel needs of faculties and students. From the perspective of travel agencies, improving product quality and services to meet the needs of university customers is necessary condition for strengthening their own abilities. They could form a new type of supply-demand relationship.

Campus reception is an important entry point for cooperation between university and student travel agencies. They can sign long-term cooperation contract for campus reception services through the form of service purchase. University student travel agencies provide professional campus reception service and regularly perform training to improve the quality of campus reception.

\section{1) Provide professional internship opportunities}

The students of the Department of Tourism and Culture are Shenzhen University's specialized tourism talents. For a long time, they have applied for professional internships usually from July to October, namely the tourism on season. However, in order to release the shortage of manpower, STA could train the tourism major students, provide practical internship opportunities for them.

\section{2) Cooperation with SUTA}

Shenzhen University Tourism Association (SZUA) is the only tourism association in Shenzhen University. With the professional background of the Department of Tourism, STUA has unique advantages in tourism product design and tourism market information, can play key role in the knowledge platform and tourism route promotion.

By means of work-study programs, line discounts, etc., members of SZUA are provided with part-time opportunities, such as event sponsorship and other forms. SZTU promotes tour productions through activities such as event promotion, WeChat public number promotion, campus poster promotion and flash events.

\section{Advertising and marketing strategy}

STA has much more space for improvement in product promotion. In light of the actual situation, the following are recommended for product promotion and marketing:

1) Create websites and exchange communities

Using the Internet for daily communication, data searching, and resource sharing have become the most common ways of life for university students. In order to facilitate college students to understand tourism products and to further enhance the reputation of college travel agencies, travel agencies must carefully establish and build official websites. Divide special communication areas or set up stickers, build service platforms such as WeChat Group and QQ Group for students who need to travel together, provide regular travel exchanges, facilitate the implementation of travel plans, and provide practical travel services [7].

2) Achieve long-term cooperation with school media

At present, Shenzhen University's most influential media are "Shenda Tong" and "Shenda Lizh". The fans of these two media cover more than $80 \%$ of faculty and student in Shenzhen University. Make full use of self-media resources to conduct full range of product promotion for college student travel agencies.

\section{3) Use university community resources}

The short-distance travel of the community is an important part of the travel agency market for college students. Shenzhen University has 100 campus communities and 6,000 college students. The influence of the teams should not be underestimated. STA should seek the cooperation of campus clubs, sponsor activities, co-organize events, provide travel discounts to clubs, and integrate college student travel agencies advertisements and publicity in corporate performances and publicity.

\section{4) Establish a three-dimensional marketing system}

Flexible marketing methods are important ways for college travel agencies to obtain successful operations. University travel agencies should build a three-dimensional marketing model to expand the campus tourist market. It can make full use of three-dimensional marketing in the network sales and physical sales [8].

Online sales can be ordered through convenient methods commonly used by undergraduates such as WeChat public account, QQ group, micro shop, and Taobao shop. The entity sales can be sold through the campus agency according to the size of the potential consumption. Different levels of signing rates are different. Each level is directly signed by face-to-face contact with the college students, being responsible for the travel process and feedback. 


\section{CONCLUSION AND OUTLOOK}

This article takes STA as an example, carries out a comprehensive analysis of the status quo of the development of university student travel agencies, and lists the SWOT analysis matrix. According to the results of the questionnaire survey, suggestions were made on the improvement of travel agencies in Shenzhen University from various aspects such as overall layout strategy, alliance strategy, product strategy, and promotional marketing strategy.(as Figure 1 shows)
The status quo of STA, to a certain extent, also represents the development of university student travel agencies in China. It can provide practical guidance for the healthy future of college student travel agencies. Due to limited time and energy, there are many problems such as the insufficient number of survey samples and the particularity of the research objects. This study will continue to focus on the follow-up of the improvement and upgrade of university student travel agencies, strengthen theoretical development and field research, and provide real and reliable experience for travel agencies in major civil universities.

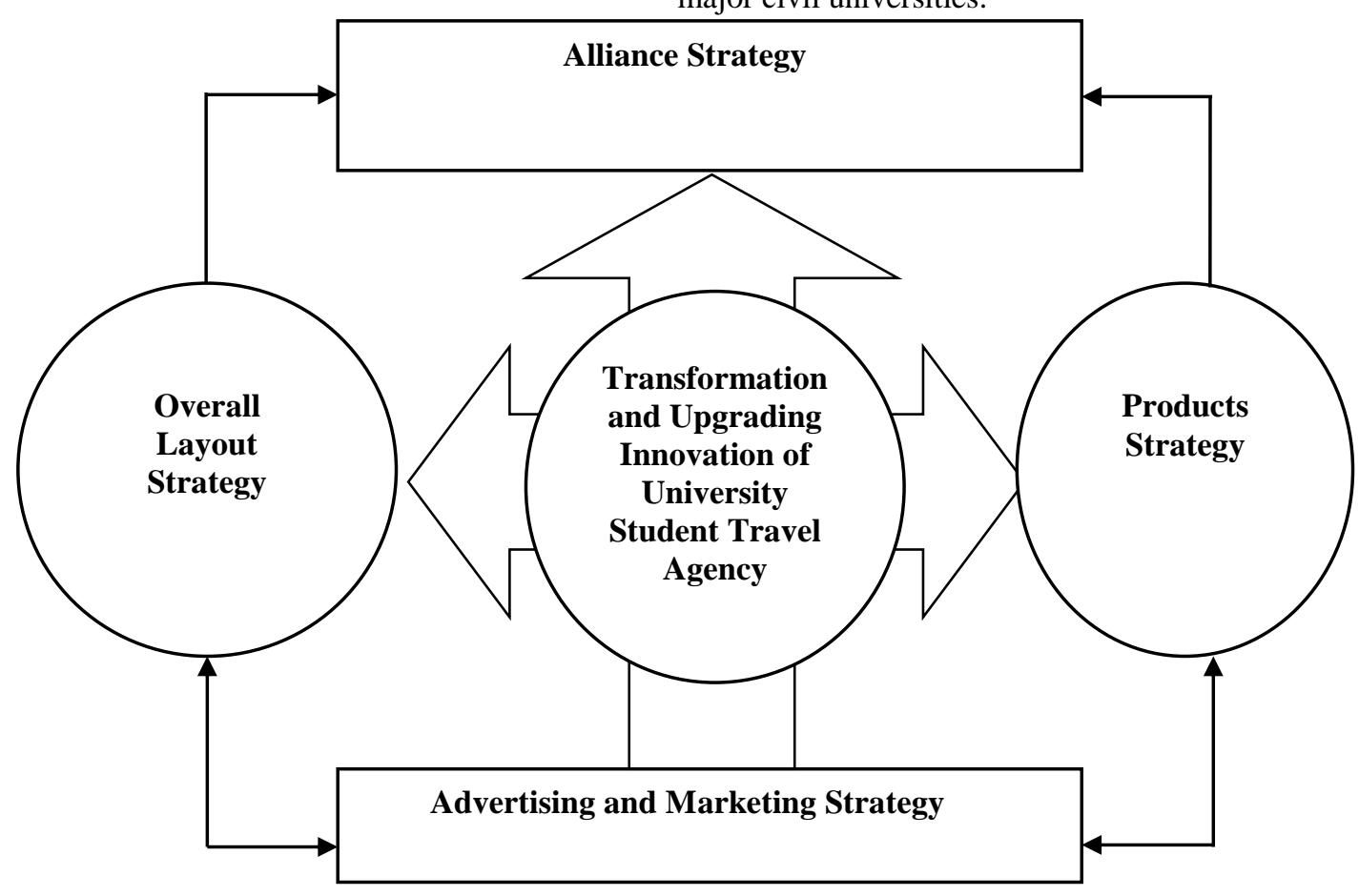

Fig. 1. Schematic Diagram of Transformation and Upgrading Strategy for STA

\section{ACKNOWLEDGMENT}

This research was financially supported by Guangdong Higher Education Teaching Reform Project Foundation (201627334) and Guangdong Provincial Undergraduate Training Programs for Innovation and Entrepreneurship (2017087).

\section{REFERENCES}

[1] Hong Yan. Research on the Development Strategy of College Students' Tourism Market in China [J]. China Business, 2010, (23): 164, 253. DOI:10.3969/j.issn.1005-5800.2010.23.106.

[2] Wang Shuang. Analysis of College Students' Tourism Consumption Behavior [J]. Modern Economic Information, 2017, (33): 1-2, 5.

[3] Fan L L. Analysis of the tourism market of college students in China [J]. China Business, 2010, (23):161-162. DOI:10.3969/j.issn.10055800.2010.23.104.
[4] Wang Linli. Research on the Problems and Countermeasures of Undergraduates' Travel Industry Entrepreneurship: Taking a University as an Example [J]. Chinese Commercial Theory, 2017, (34):187-188.

[5] Moreo, J. (2006). Internet travel booking activities among college students (Order No. 1440412). Available from ABI/INFORM Collection; ProQuest Dissertations \& Theses Global A\&I: The Humanities and Social Sciences Collection. (304944278). Retrieved from https://search.proquest.com/docview/304944278?accountid=13833

[6] Shenzhen University Student Creative Park Entrepreneurship Support Policy [EB/OL]. http://cyy.szu.edu.cn/WebSite/list/18.html.

[7] Lin Xueni, $\mathrm{Li}$ Hongwei. Research on Internet marketing entrepreneurship in college student travel market [J]. Chinese Commercial Theory, 2017, (35):53-55.

[8] Salih, T. K., Mehtap-Smadi, S., Kilinç, C., \& Dogan Ünlücan. (2012). Service quality and university students' satisfaction on the travel agencies. International Journal of Quality and Service Sciences, 4(3), 299-311. doi:http://dx.doi.org/10.1108/17566691211269602. 